\title{
Evaluation of the structural behaviour of historic masonry buildings by using a sonic pulse velocity method
}

\author{
F. Casarin, M. R. Valluzzi, F. da Porto \& C. Modena \\ Department of Structural and Transportation Engineering, \\ University of Padova, Italy
}

\begin{abstract}
Sonic pulse velocity tests are mainly used in historic masonry structures for consistent diagnosis evaluations and checking of the effectiveness of strengthening interventions. In this paper, results obtained from sonic tests applied on two historical constructions, namely the cathedral of Reggio Emilia and the bell-tower of the S. Zeno basilica in Verona, Italy are presented, to allow structural models being calibrated on an experimental basis for the definition of the behaviour of the buildings. The sonic investigation method is preliminarily discussed in the light of the outcomes of an EU research comprehensive project, also aimed at the identification of capability and limits in applications in the historical heritage field.

Keywords: non-destructive techniques, experimental investigation, historical masonry structures, FE modelling, sonic pulse velocity test.
\end{abstract}

\section{Introduction}

The sonic pulse velocity method is a rather established technique for the in-situ diagnosis and for the evaluation of the effectiveness of the interventions applied to historical masonry buildings (Rilem [1]). It is a fully non-destructive technique, thus it does not present any risk of damage for the building.

Sonic waves are used for preliminary investigations in masonry to identify internal cohesion among materials, in order to derive the presence of voids or damage, thus obtaining important indications for the possible most suitable consolidation intervention (e.g., injectability checking of the wall, etc.). 
By extension to some data-base and studies available on NDT (Non Destructive Test) results systematization, and by comparison with results obtained by the concomitant application of other NDT (e.g., radar, endoscopies, thermography, etc..) or MDT (Minor Destructive Tests) (e.g., flat jack tests, coring, etc.), different typologies of masonry (stone, clay bricks), quality of materials (rubble, regular, inhomogeneous combinations, etc..) and specific morphologic or constructive aspects (multi-leaf sections, soundness of intersections, etc.), can be qualitatively identified. On the contrary, due to the large variability of masonry materials, quantitative results are rather difficult to obtain in historic structures (D11.1 - Onsiteformasonry [4]); in such field, only the direct comparison among velocities acquired in different portions of the wall investigated in the same conditions (e.g., to qualify the current state of masonry for diagnosis purpose), or of the same portion in different conditions (e.g., before and after a consolidation intervention, to verify its effectiveness) can propose results considered quantitative.

Although several researches have been carried out on this subject, it is still confirmed the unreliability of absolute correlations between the sole velocity and a specific identification of a masonry and/or of a state of consistency of it.

Sonic test results can be therefore usefully utilized to improve structural characterizations by numerical modelling (aimed at identifying the mechanical behaviour of buildings or, more locally, at component level), but whose reliability is often very low for masonry constructions, especially in damaged conditions.

In the paper, various test configurations (direct, tomography) are applied to two historical constructions in Italy, namely the Cathedral of Reggio Emilia and the bell-tower of the S. Zeno church in Verona, to calibrate structural models for the identification of their mechanical behaviour.

A deep investigation of the several aspects involved in the application of NDT and MDT techniques (equipment, test configurations, results processing, comparison between different techniques) was performed in the framework of the European funded project "On-Site Investigation Techniques for the Structural Evaluation of Historic Masonry Buildings" - ONSITEFORMASONRY - [7], which complied in-situ and laboratory applications to several historic masonry structures located in different parts of Europe. The main issues of the project, with particular attention to capability and limits of test applications in historical sites are resumed in the following.

\section{Methodology, applicability and limitations}

The sonic pulse velocity method is applied for measuring the transit time of sonic pulses (stress waves) in masonry structures. This transit time and the calculated sonic pulse velocity result in basic information about the quality and consistency of the masonry element under investigation. The velocity is influenced by the composition of the masonry as well as by the presence of inhomogeneities, voids and deteriorated areas (D11.1 - Onsiteformasonry [4]). 
Some works show that a certain relationship can be found between the sonic pulse velocity and the modulus of elasticity of the masonry (Riva et al. [3]). However, this relationship varies according to the given masonry typology and texture, and it has to be stressed that statistical database for rough estimations of elastic properties from velocity values are still in a very experimental phase.

The sonic pulse velocity test can be carried out in different ways, according to the different transmission methods. The direct transmission method for sonic waves involves passing of a stress wave through the thickness of the masonry wall. The initiation and reception points of the stress waves are in line with each other, on opposite sides of the masonry element. The sonic pulse velocity detected is thus affected by the quality and consistency of the masonry wall section. It is also possible to carry out sonic tomographies, where the measurement of sonic pulse velocities are combined along different ray-paths on a cross section of masonry, and are subsequently processed in order to define mean values of velocity on each portion of the wall section itself.

The chosen testing configuration depends on the matter of the investigation, such as, for example, the detection of masonry inhomogeneities (e.g., variation of masonry texture, repair interventions, presence of different materials...), detection of multiple leaves and measurement of the thickness of each leaf, detection of detached external leaves, detection of voids or chimney flues, evaluation of effectiveness of repair interventions, detection of damaged portions of masonry or of crack patterns.

The frequency associated with the sonic tests $(20-20.000 \mathrm{~Hz})$, together with the wavelength affects the minimum size flaw that can affect the transmission of a sonic pulse (Epperson and Abrams [2]). The method then fails when its resolution is not sufficient for the aims of the investigation, and this can happen if detection of small voids or small inclusions is required, or in some cases when dealing with the detection of multiple leaves, of detached external leaves, of cracks, etc.

\section{Applications to historical masonry structures}

Sonic Pulse Velocity Method was applied in combination with other techniques for the acquisition of important structural information on several masonry buildings, aiming at the successive assessment by means of structural models. Under the activities of the EU funded project "Improving the Seismic Resistance of Cultural Heritage Buildings [8], the cathedral of Reggio Emilia, Italy, underwent an extensive investigation campaign, including sonic tests (Semenzato [5]). Subsequently the structural behaviour of the building was simulated by means of analytical and numerical models.

The second case study is the bell-tower of the S. Zeno basilica in Verona, Italy. In this case, the application of sonic tests in tomographic configuration was considered for the evaluation of the inner composition of the belfry " $L$ " shaped pillars, as a preventive evaluation related to a strengthening intervention of the roof and bells' supporting structure of the tower (Scodeller [6]). 


\subsection{Santa Maria Assunta cathedral, Reggio Emilia, Italy}

The origins of the Reggio Emilia cathedral are to be found at the half of the IX century. The structure was based on the pre-existences of an early Christian church. The original plan of the church corresponds to a "Latin cross" typology, with three naves and transept. Throughout the centuries the cathedral underwent several interventions that substantially altered the original construction. The principal modifications corresponded to: the extension of an atrium to the original façade, with a superimposed dome lantern (XIII c.); the erection of chapels along the aisles, between the mid XV century and the end of the XVI, and the raising of the dome lantern (1451); the raising of the aisles' vaults, the elimination of the Romanesque women's gallery (1551-1559) and the inclusion of the original Romanesque columns inside "new" massive cruciform pillars; the substitution of the ancient dome lantern positioned at the nave/transept crossing with a dome (1624-1626), and the complete substitution of the pre-existing cross-vaulted structures, both in the central nave and in the aisles, with the construction of barrelled vaults (1777).

The cathedral presents an original Latin cross plan, with central nave, two aisles and transept. The length of the church is $77.40 \mathrm{~m}$, the width is $33.80 \mathrm{~m}$, the span of nave and aisles is $10.15 \mathrm{~m}$ and $6.50 \mathrm{~m}$, respectively. The maximum height is reached at the top of the dome, with $44.60 \mathrm{~m}$; the height of the façade dome lantern is $33.80 \mathrm{~m}$ and the height of the roof above the central nave corresponds to $22.25 \mathrm{~m}$. The cathedral is mainly composed by clay brickwork masonry. The diverse constructive phases comported the use of different materials, and some structural elements or parts (e.g. Romanesque pillars, lower façade veneers) are made of stone (Figure 1).

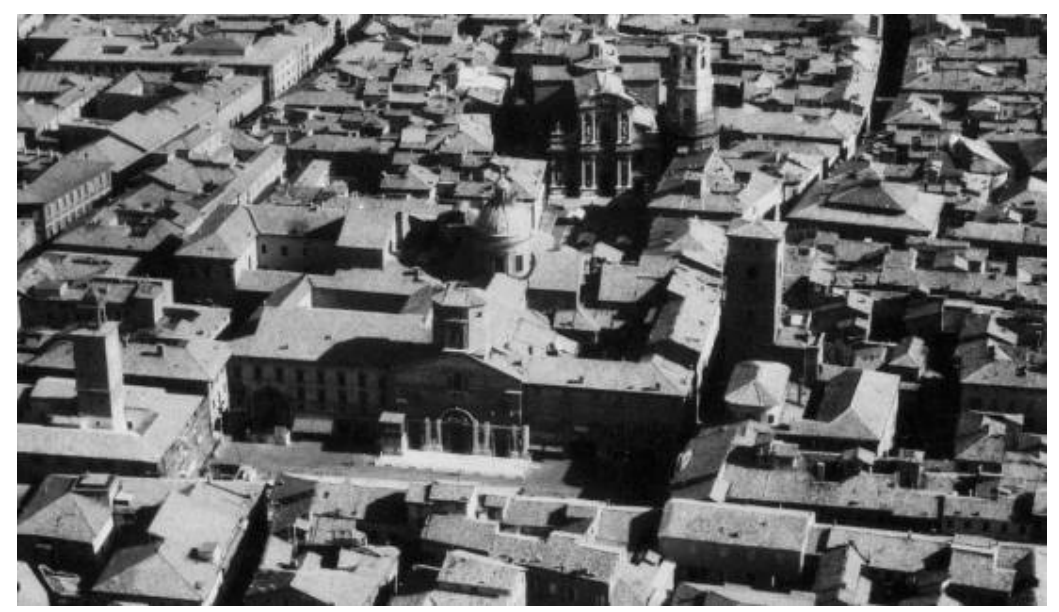

Figure 1: Santa Maria Assunta cathedral in the city centre of Reggio Emilia.

Sonic tests were extensively carried out on the Cathedral's masonry structures (2005). The main aim of the sonic investigation campaign was to qualitatively 
define the masonry conditions at the tested points, in order to proceed with the successive phase of structural assessment.

As a starting point, a sonic direct test was executed in correspondence of the masonry pillar previously tested by means of double flat-jack. Considered the several structural interventions that modified the original layout of the religious complex, comporting changes in materials and constructive techniques, any correlation between data emerged from sonic tests to variation in terms of elasticity modulus was not established, since the procedure was not considered reliable. Sonic tests localization is given in Figure 2.

Sonic tests were aimed at the qualification of the inner composition of the analyzed structural elements, since all of the tests were carried out in direct configuration. Data emerged from the application of the method to wide portions of the complex denoted globally fair velocity results, indicating possible fair mechanical characteristics. In terms of minimum values encountered, seldom the velocity was lower than $800 \mathrm{~m} / \mathrm{s}$.
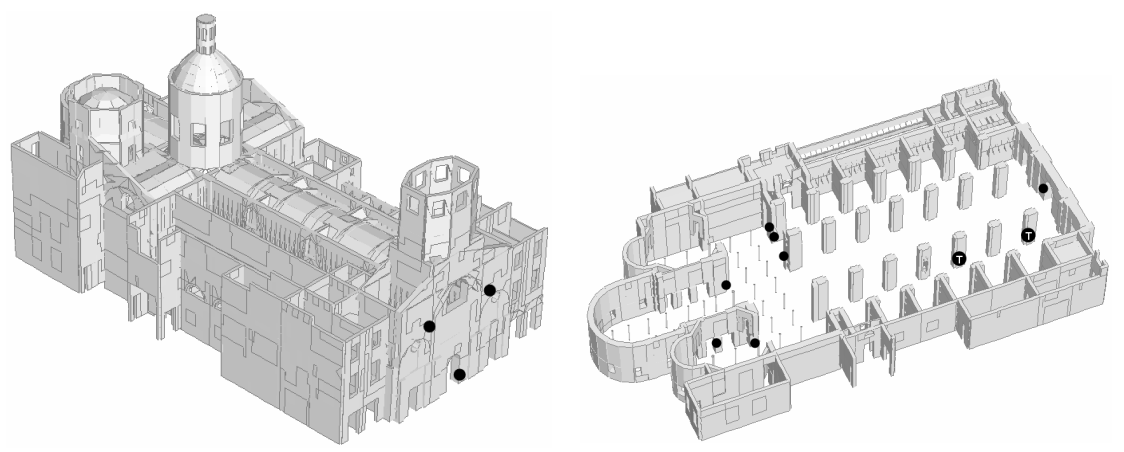

Figure 2: Reggio Emilia cathedral, Sonic tests, localization.

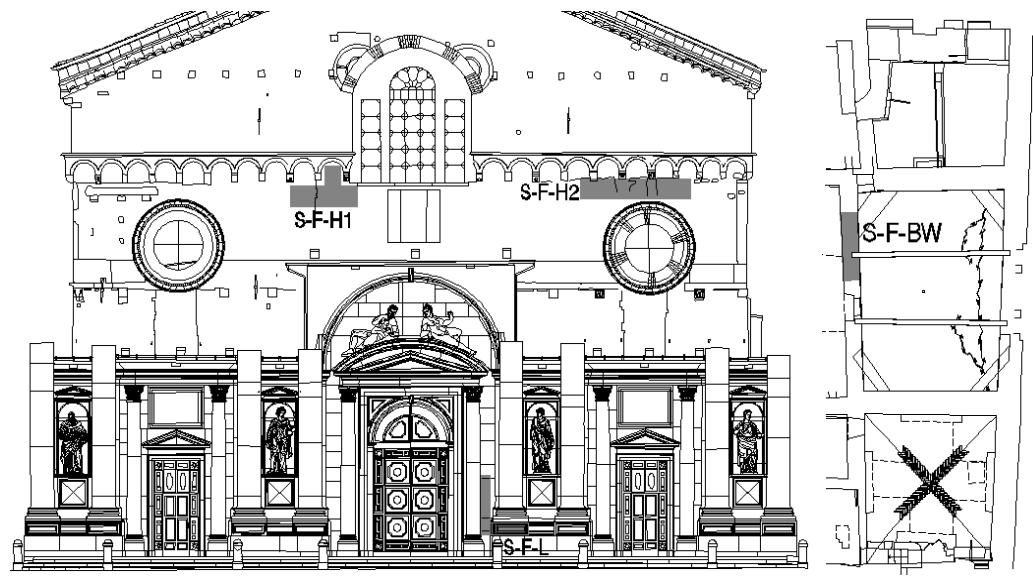

Figure 3: Positioning of sonic direct tests, Façade (elevation) and dome lantern back wall (plan view). 
No odd velocity values were found, denoting absence of macroscopic inconsistencies within the tested masonry portions investigated. Several masonry walls tested denoted a general velocity uniformity, indicating a possible uniformity also in terms of mechanical characteristics, resulting in a positive homogeneous stress pattern. This was particularly evident in tests S-F-H1/H2, where a façade horizontal slice $17 \mathrm{~m}$ long was analyzed at the same height, denoting rather uniform velocity values (Figure 3 ).

A noticeable data scatter was noticed in correspondence of areas subjected to past restoration interventions, as is the case of the façade lantern back wall. Sonic results obtained in the lower part of the façade (test S-F-L) are indicative of a possible masonry variable inner configuration. Sonic velocities obtained in the upper façade tests $(\mathrm{S}-\mathrm{F}-\mathrm{H} 1 / \mathrm{H} 2)$ presented an overall value of $1215 \mathrm{~m} / \mathrm{s}$, averaged on 61 paths, in line with data emerged from the upper lines of test S-FL. In some cases it was possible to appreciate that the analyzed structures presents a multi leaf structure, being this denounced by the marked difference in terms of velocity recorded in the superficial path respect paths crossing the inner section of the analyzed wall/pillar (Figure 4: tests S-C-FJ, S-N-D1/D2). Confirmation of this comes from the examination of the core samples extracted in the crypt's area.

Sonic investigations results, related to the brickwork masonry typology, proposed the final impression (overall average velocity $1394 \mathrm{~m} / \mathrm{s}$ on 349 sonic paths) that the successive implementation of structural models resorting from limit analysis approach, considering the selected masonry portions (macroelements) as rigid bodies, was possible, since the tested masonry portions did not denounce severe structural deficiencies, possible cause of sudden collapse (e.g. masonry crumbling) before the beginning of the considered mechanisms.
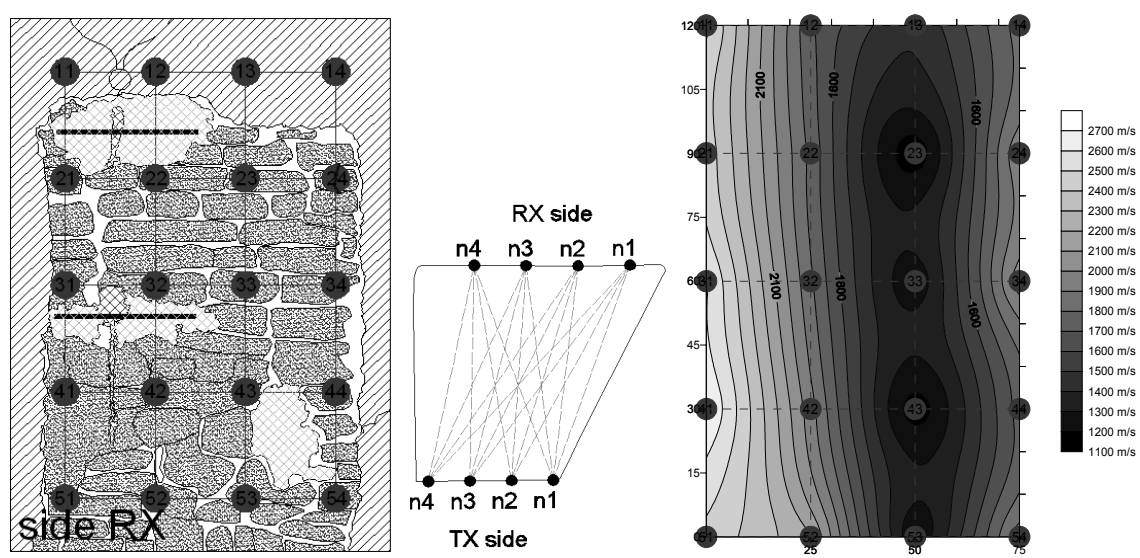

Figure 4: Reggio Emilia cathedral, crypt level: direct sonic test, acquisition grid, sonic paths and obtained velocities. 


\subsection{San Zeno bell-tower}

The S. Zeno basilica is one of the most important and known churches of Verona, being dedicated to the patron saint of the city. The origins of the early settlements of S. Zeno are related to the church and coenoby erected on the roman and early Christian graveyard area, close by the via Gallica, built on the burial place of the bishop Zeno (362-380 AD) to keep its memory and holy relics. The original buildings went through reconstructions during the VI c., and in 805-6 AD the church was widened and a monastery was built close by.

After the destruction perpetrated in 963 AD by the Hungars, the church was built again (983 AD), with three naves, three apses and crypt, reaching its definitive width. At the end of the XI c. the church was extended and renewed with a Romanesque style. Interventions continued along the XII and XIII centuries (further extensions, raising of the façade, creation of the rose window), and in 1387 the apse and roof were demolished and rebuilt with Gothic features (Figure 5).

On the right side of the basilica and separated from it, the bell-tower rises to a height of $66 \mathrm{~m}$. Erected in $1045 \mathrm{AD}$ and repaired in 1120 (after the 1117 earthquake), was finished in 1178. Above the base it presents the characteristic alternation of colours due to the sequential use of calc-tufa stones and brickwork bands. The rhythm of the bell-tower is marked by cornices decorated with tuff stone arches and it is crowned by a double order of thee mullioned windows and by a spire with 4 side pinnacles.

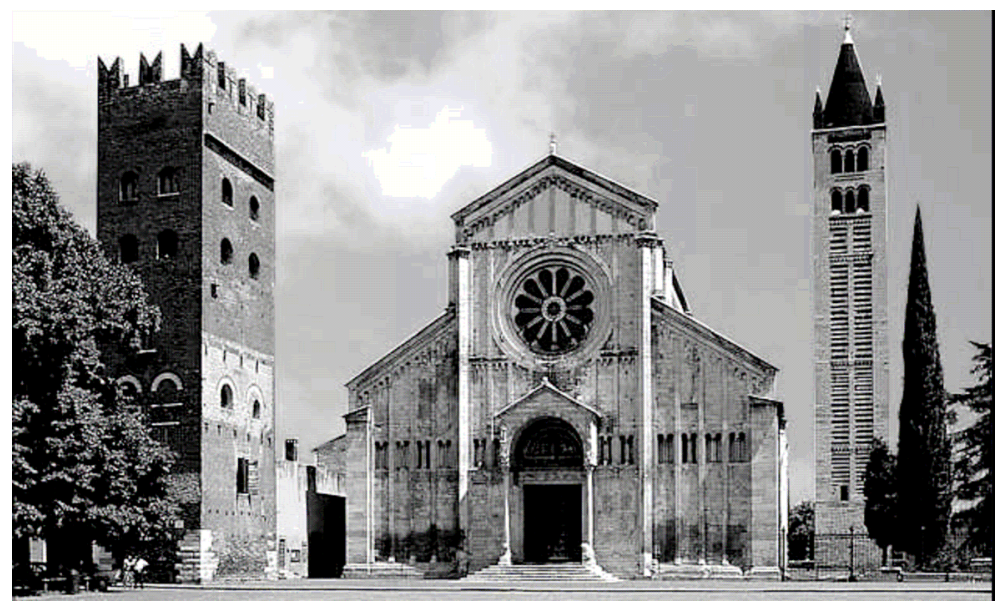

Figure 5: S. Zeno basilica, façade. On the background, on the right, the belltower.

As a support for the strengthening intervention successively carried out on the S. Zeno bell-tower (2006), a deep study on the conditions of the belfry's structural elements, with a particular eye on the masonry pillars sustaining the massive spire, whose degree of structural decay was outlined by preventive 
analyses (deterioration of the mortar joints caused by the rain and ice-thaw cycles, evident crack pattern, interaction with the structure supporting the bells), was carried out.

In particular, sonic tomographies at two different levels of an "L" shaped pillar of the upper level of the belfry (Figure 6) were applied (respectively at 0.55 and $1.85 \mathrm{~m}$ from the belfry floor) to have an insight on the inner composition of the masonry structural elements. Both of the two tests indicate that the inner part of the pillar is composed by a masonry with supposed reduced masonry consistency/different composition respect the external area, being this denounced by the different velocities emerged from the analysis (avg. velocity of the inner and outer areas corresponding respectively to approximately 1800 and $2500 \mathrm{~m} / \mathrm{s}$ in the lower cross section and 1600/2600 m/s in the higher).

Such results, corroborated by the successive extraction of core samples in the area of execution of the tests, can be related to the presence of brickwork masonry in the inner part, presenting a velocity that generally denotes a material with fair/good mechanical characteristics, and an outer masonry composed by well arranged sandstone masonry blocks (Figure 7). Consequently to the outcomes of the investigation phase, structural FE linear models of the investigated pillar, simulating the dead load and thrust of the spire, as well as the horizontal action of the swinging bells, and considering different materials throughout the cross section as emerged, were implemented. From the numerical analysis it emerges that the pillars is subjected to compressive stresses ranging from approx. 2.0 (in its external sides - respect the belfry - and inner core) to 3.0 $\mathrm{MPa}$ (in the sides towards the inner belfry), these evaluations giving the possibility to determine the safety state of the pillar and influencing the successive phase of strengthening intervention planning (Figure 8).
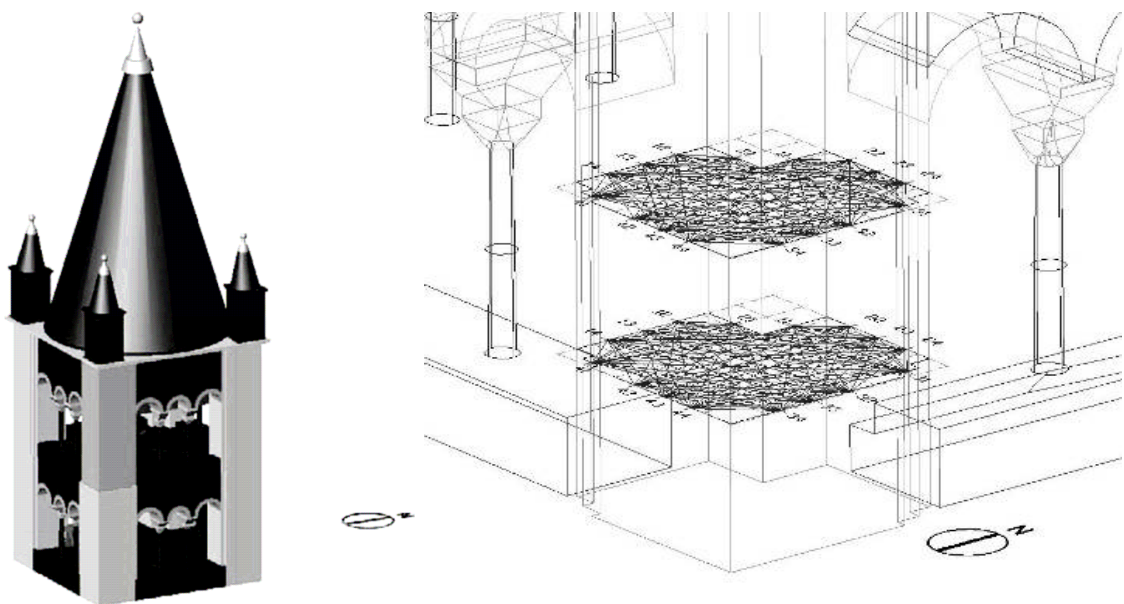

Figure 6: S. Zeno bell-tower: localization of the pillar interested by sonic testing and tomographic sections with indication of the sonic paths. 


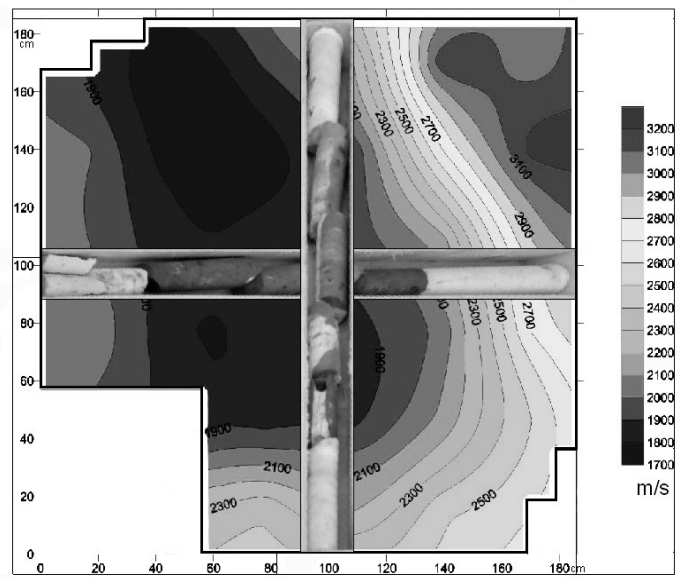

Figure 7: Lower sonic tomography, S. Zeno bell-tower, Verona: velocities are related to masonry composition by means of core samples extraction.
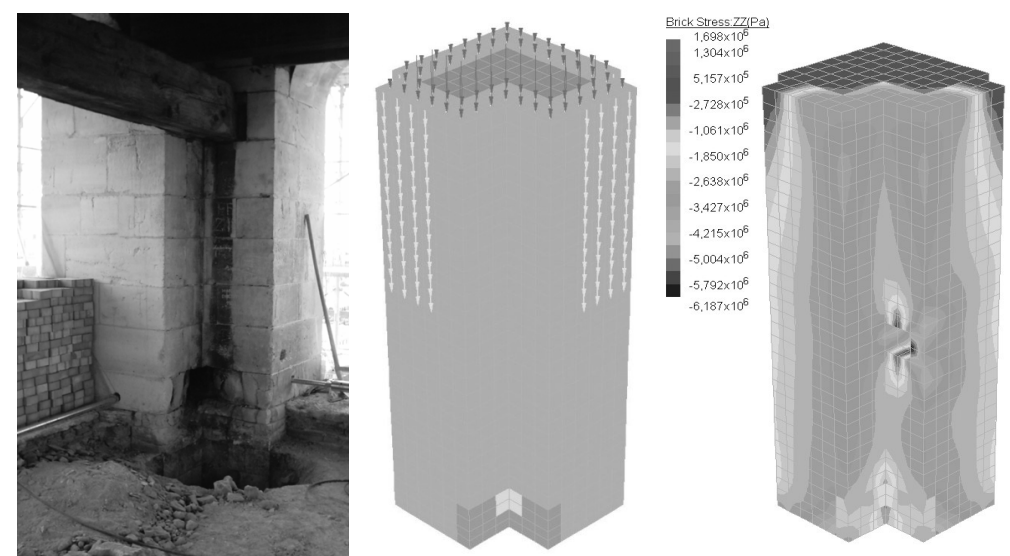

Figure 8: View of pillars of St. Zeno tower belfry and corresponding pre and post processed FE model.

\section{Conclusions}

From the experience acquired, it emerged that the sole application of sonic tests, considered their characteristics of ND tests, does not allow a confident implementation of structural models, in the sense that several issues implying a mechanical evaluation and assessment can not be solved just by the definition of the sonic velocity within the structural elements of a historical masonry building.

More information may arise from the evaluation of the sonic tomography, whose velocity detection may be indicative of different typology masonry thus also with different mechanical parameters. 
Also, it emerged that ND methodologies such as sonic tests have possibly to be complemented with other (MD) techniques necessary for a results generalisation in order to proceed with the successive phase of structural assessment.

Finally, it can be said that the most appropriate testing methodology is strongly dependent on the expected results of the acquisition campaign. In the case of the Reggio Emilia cathedral, a wide application of the sonic method (direct configuration) was necessary for the general implementation of limit analysis models used to defined the seismic response of the building. In the case of the S. Zeno bell-tower in Verona, a more detailed analysis (sonic tomography) interested a single structural element to solve a local FE modelling problem.

\section{Acknowledgements}

The research work reported in the paper was mainly carried out under the activities of the EU funded projects "Improving the Seismic Resistance of Cultural Heritage Buildings" [7] and "ONSITEFORMASONRY" [8].

The authors would like to gratefully thank engineers Davide Semenzato and Matteo Scodeller for their collaboration for on-site tests and data processing.

\section{References}

[1] RILEM Recommendation TC 127-MS. MS.D.1 Measurement of mechanical pulse velocity for masonry, published in Materials and Structures, Vol. 29, pp. 463-466, 1996.

[2] Epperson, G.S. \& Abrams, D.P., Non destructive evaluation of masonry buildings, Advanced Construction Technology Center, Doc. N. 89-26-03, Urbana Illinois, 208 pp., 1989.

[3] Riva, G., Bettio, C., Modena, C., Valutazioni quantitative di caratteristiche meccaniche di muratura in pietra esistenti mediante prove non distruttive. Materiali e Strutture, L'ERMA di Bretschneider Ed., n. 1, 1998 (in Italian).

[4] Deliverable D11.1 (2004): Technical guidelines for an appropriate use of the suggested equipment. ONSITEFORMASONRY, Project $\mathrm{n}^{\circ}$ EVK4-200100091, Contract $n^{\circ}$ EVK4-CT-2001-00060, 2004.

[5] Semenzato, D. Indagini strutturali e verifica della vulnerabilità sismica della chiesa di S. Maria Assunta a Reggio Emilia. Graduation thesis, Tutor Prof. MR. Valluzzi, University of Padua, 2006 (in Italian).

[6] Scodeller, M., Indagini soniche per la diagnosi di strutture murarie a torre. Graduation thesis, Tutor Prof. MR. Valluzzi, University of Padua, 2006 (in Italian).

[7] EU funded research project ( $5^{\text {th }}$ Framework Programme) "On-site investigation techniques for the structural evaluation of historic masonry buildings, Project Acronym: ONSITEFORMASONRY, Project Reference: EVK4-CT-2001-00060, http://www.onsiteformasonry.bam.de.

[8] EU funded research project (EU-India ECC Programme) "Improving the Seismic Resistance of Cultural Heritage Buildings", Contract ALA-95-232003-077-122, http://www.civil.uminho.pt/eu-india. 